\title{
Ascorbic acid encapsulation in a glassy carbohydrate matrix via hot melt extrusion: Preparation and characterization
}

\author{
Dawei CHANGㅁ, Khizar HAYAT ${ }^{2}$, Shabbar ABBAS ${ }^{3 *}$ (D), Xiaoming ZHANG ${ }^{4}$
}

\begin{abstract}
Hot melt extrusion technology using a twin-screw extruder was employed to obtain maltodextrin, maltodextrin-gum arabic and maltodextrin-trehalose based glassy extrudates containing ascorbic acid (dispersed phase). Ascorbic acid payload of all three formulations was more than $15.67 \mathrm{~g} / 100 \mathrm{~g}$ extrudates while the ascorbic acid yield was above $97 \%$. The glass transition temperature $(\mathrm{Tg})$ of all extrudates was above $40^{\circ} \mathrm{C}$. The expansion ratio of the extrudates and $\mathrm{Tg}$ reduced due to the incorporation of trehalose and gum arabic to maltodextrins, respectively. The results of Scanning Electron Microscopy, X-ray diffraction and Fourier-transform Infrared Spectroscopy confirmed that the formulated feed material turned into a glassy state, whereas, ascorbic acid was uniformly dispersed throughout the glassy matrix. Extruded formulations showed a steady dissolution rate, therefore, having a role in controlling the dissolution rate of ascorbic acid.
\end{abstract}

Keywords: ascorbic acid; encapsulation; melt-extrusion; maltodextrins; glass transition temperature.

Practical Application: Carbohydrate matrices in a glassy state offer protection to the encapsulated ascorbic acid in it, allowing the use of this vitamin in different food formulations.

\section{Introduction}

Ascorbic acid (AA) is a water-soluble compound which is essential for the normal regulatory functions of a human body. Humans have lost the ability to synthesize AA. Thus, AA must be obtained through the diet for healthy life. Although fruits and vegetables are good sources of AA, it is partially destroyed due to oxidation during post-harvest and processing conditions. To compensate this, food is often fortified with AA to meet Recommended Daily Allowances (Carr \& Frei, 1999; Silva et al., 2018). However, benefits of fortification are spoiled by the fact that AA is highly unstable and interactive towards other food components, thus, destabilizing the whole food system.

Variety of encapsulation techniques has been introduced for the protection and delivery of AA, as reviewed by Abbas et al. (2012). Among these, hot-melt extrusion (HME) technology is being widely used by the pharmaceutical industry to preserve labile bioactives, including AA (Gouin, 2004; Chang et al., 2010; Tackenberg et al., 2014; DiNunzio et al., 2016). HME is a continuous and cost-effective process that involves feeding polymeric materials to extruder with a rotating screw at temperatures above their glass transition temperature $\left(T_{g}\right)$. The basic idea behind this technique is to exploit the $T_{\mathrm{g}}$ of carbohydrates in which the active agents (gas, liquids, solids) are dispersed or dissolved. Therefore, HME can be used to encapsulate unstable bioactives in glassy carbohydrate matrices (Yllmaz et al., 2001; Chang et al., 2010; Emin et al., 2012; Emin \& Schuchmann, 2013; Chuah et al., 2014; Al-Kasmi et al., 2017).
However, to our knowledge, no work has been reported to produce maltodextrin-gum arabic and maltodextrin-trehalose based glassy matrices (through HME technology) for the encapsulation of AA. Therefore, aim of the present study was to develop new carbohydrate blends and to investigate their influence on the solid state of the processed matrices for AA encapsulation. In this context, major objective is to stabilize AA in carbohydrates matrices prepared from biopolymer-based novel formulations. We hypothesize that the glassy matrices of selected carbohydrate material may offer improved barrier properties to dispersed AA, thereby, decreasing the chance of unwanted interactions of AA with its environment. This acquired stability would allow food processors to use encapsulated AA as a fortificant in different food formulations.

\section{Material and methods}

\subsection{Materials}

Maltodextrins of DE 10-15 was obtained from Baolingbao Biology Co., Ltd, Yucheng, China. Hangzhou Jinchengzhuji Co., Ltd, Hangzhou, China provided the medium chain triglycerides (decanoic acid ester with 1, 2, 3-propanetriol octanoate). Soy lecithin was the product of Solae Company, US. Ascorbic acid was purchased from CSPC Pharmaceutical Group Lid, Shijiazhuang, China. CNI provided gum arabic while Hayashibara Co., Ltd, Okayama, Japan supplied trehalose. All other chemicals were of analytical grade (Sinopharm Chemical Reagent (SCR) Co., Ltd, Shanghai, China). 


\subsection{Material preparation and mixing process}

Initially, oil-water emulsion was prepared for the development of each formulation. MCT was used as an oil phase while soy lecithin acted as an emulsifier. Briefly, oil phase was prepared by slowly adding the liquid emulsifier into MCT oil, while stirring continuously using a mixer (RW20 Digital, Germany) at $200 \mathrm{rpm}$ for 5 minutes at room temperature. To this mixture, distilled water was slowly added and stirred at $200 \mathrm{rpm}$ for 30 minutes until the emulsion was formed. Next, the prepared emulsion was mixed with the rest of solid ingredients (maltodextrins, gum arabic, and/or trehalose) in a high-speed mixer (DFY-500, China) for $1 \mathrm{~min}$ at 10,000 rpm to ensure the uniform dispersion of ingredients. MCT in the formulation was meant to enhance the melt rheology and slippage of the molten mass during extrusion process. The composition of each formulation is shown in Table 1. Prior to extrusion, all formulations were passed through a 30-mesh screen sieve to remove lumps.

\subsection{Extrusion trials}

Experiments were performed using a co-rotating twin-screw extruder (Die diameter: $3 \mathrm{~mm}$ ) consisting of four barrels with a length-to-diameter ratio of 24 with intermeshing screws (HAAKE PolyLab System, PTW24/25D, USA). The obtained premix in each formulation were fed into the extruder inlet port by a screw feeder (DDSR20N-PRISM, Germany). The measuring feeder was set to obtain a flow rate of $1.1 \mathrm{~kg} \mathrm{~h}-1$ of feed mixture and screw speed was maintained at $60 \mathrm{rpm}$ for all the runs. For all experiments, temperature along the extruder barrel was set at $85^{\circ} \mathrm{C}$ (zone 1), $105^{\circ} \mathrm{C}$ (zone 2), $120^{\circ} \mathrm{C}$ (zone 3 ) and $105^{\circ} \mathrm{C}$ (zone 4 ), respectively. The barrel section's temperature and die head pressure, torque, torque percent, material temperatures between zone 2 and zone 3 (TM1), material temperature between zone 3 and zone 4 (TM2) of extruded material for each formulation were recorded to assess the ease of extrusion. After extrusion, the obtained extrudates were subsequently air-cooled at room temperature and crushed at $6000 \mathrm{rpm}$ in a centrifugal mill (Retsch ZM 200, Haan, Germany). The powder was divided into three fractions ( $<20$ mesh, 20-40 mesh and $>40$ mesh) by sieving and stored for further analysis.

\subsection{Differential scanning calorimetry}

A device equipped with a nitrogen cooling system (PerkinElmer Pyris 1, US) was used to record the differential scanning calorimetry (DSC) curves. Ultrahigh purity nitrogen was used as the purge

Table 1. Composition (\%,w/w) of each formulation prepared for extrusion.

\begin{tabular}{lccc}
\hline & \multicolumn{3}{c}{ Composition (\%) } \\
\cline { 2 - 4 } & Formulation 1 & Formulation 2 & Formulation 3 \\
\hline Maltodextrin & 80.5 & 78.5 & 70.5 \\
Gum Arabic & - & - & 10 \\
Trehalose & - & 2 & - \\
AA & 16 & 16 & 16 \\
MCT & 1 & 1 & 1 \\
Added Water & 2 & 2 & 2 \\
Soya Lecithin & 0.5 & 0.5 & 0.5 \\
Total & 100 & 100 & 100 \\
\hline
\end{tabular}

gas at a flow rate of $20 \mathrm{~mL} /$ minute. Samples (around $10 \mathrm{mg}$ ) were pre-sealed into aluminum pans of $40 \mu \mathrm{L}$ before thermal analysis. Samples were first heated at $10{ }^{\circ} \mathrm{C} /$ minute to $90{ }^{\circ} \mathrm{C}$. The glass transition range was determined, and $\mathrm{Tg}$ midpoint was taken as the characteristic value. All determinations were performed in duplicate, and an empty pan served as reference.

\subsection{Moisture content}

The extruded samples were ground into powder. Moisture analysis was performed using "loss on drying instrument." The pre-weighed samples were placed on the aluminum pans and the drying was performed at $130^{\circ} \mathrm{C}$ under atmospheric pressure for 165 minutes (Massaux et al., 2008). The percent weight loss of the samples was recorded as the percent moisture content.

\subsection{Determination of $A A$}

Iodometric titration method was used to determine the AA content. Starch solution (0.5\%) acted as an indicator. Sodium thiosulphate $\left(\mathrm{Na}_{2} \mathrm{~S}_{2} \mathrm{O}_{3}\right)$ solution $(0.07 \mathrm{M})$ was prepared and standardized with $50 \mathrm{~mL}$ of $0.01 \mathrm{M}$ pure potassium iodate containing $2 \mathrm{~g}$ of solid potassium iodide. Iodine solution $(0.05 \mathrm{M})$ was prepared and standardized with the standard sodium thiosulphate solution $(0.07 \mathrm{M})$.

Distilled water $(100 \mathrm{~mL}), 2 \mathrm{~mol} / \mathrm{L}$ acetic acid $(1 \mathrm{~mL})$ and starch solution $(2 \mathrm{~mL})$ added into the $250 \mathrm{~mL}$ conical flask. The $0.2 \mathrm{~g}$ powder of each extrudate in triplicates, added into the conical flask and dissolved. The prepared solution was titrated with the standard iodine solution to a stable blue end-point using freshly prepared starch solution. One $\mathrm{mL}$ of $0.05 \mathrm{M}$ iodine was equivalent to $(8.806 \mathrm{mg}$ ) of ascorbic acid. The results were the average of the triplicates in each sample.

\subsection{Expansion properties}

Radial expansion was determined by measuring the diameter of extrudates through digital calipers. Expansion ratio was calculated as the extrudate diameter divided by the die diameter. The results were the average of the twenty readings in each sample (Yuliani et al., 2006; Milani et al., 2014).

\subsection{Scanning Electron Microscopy (SEM)}

Electron microscopy (QUANTA-200, PHILIPS, Netherlands) conducted to observe the cross sections of extrudates, under high vacuum and operating potential of $5 \mathrm{kV}$. The prepared specimens previously coated with a thin gold layer.

\subsection{AA yield of the extruded product}

AA yield of extrudate was calculated as the amount of AA in extrudate divided by the amount of AA added in initial formulation prior to extrusion.

\subsection{X-ray diffraction analysis}

A D-8 Advance X-ray Diffractometer (Bruker AXS) was used for X-ray diffraction (XRD) analysis. The generator voltage and current were $40 \mathrm{kV}$ and $40 \mathrm{~mA}$, respectively. The X-ray 
pattern was collected in the angular range of $3^{\circ}<2 \theta<70^{\circ}$ in the step-scan mode with step width of $0.02^{\circ}$ and scan rate of $4^{\circ} / \mathrm{min}$.

\subsection{Fourier-transform Infrared Spectroscopy (FTIR)}

Nicolet Nexus 470 FTIR spectrometer (Nicolet American) helped to obtain the FTIR spectra of AA, maltodextrins, premix material and extrudates. Hydraulic press was helpful in compressing the Sample-KBR-blends into KBr disks.

\subsection{Dissolution testing}

Dissolution testing was performed using the reciprocating cylinder method (modified USP Apparatus 2, paddle), in $900 \mathrm{~mL}$ of $0.1 \mathrm{~N} \mathrm{HCl}$, at rotation of $125 \mathrm{rpm}$. The temperature of the medium $(900 \mathrm{~mL})$ was kept at $37 \pm 0.5^{\circ} \mathrm{C}$ and all experiments were run in six replicates. Samples of $5 \mathrm{~mL}$ were withdrawn at appropriate time intervals and immediately replaced by a fresh dissolution medium. The amount of AA released from milled extrudates was quantified by Iodimetric titration method.

\subsection{Storage trial}

The extrudates were ground into powder and $20 \mathrm{~g}$ powder of each extrudate was put into $250 \mathrm{~mL}$ air-tight glass bottle and sealed. Afterwards, the samples were stored at $40^{\circ} \mathrm{C}$ for 3 months to analyze their storage stability.

\subsection{Statistics}

Data were analyzed using Microcal Origin V.7.0 software (Microcal software, Northampton, USA).

\section{Results and discussion}

\subsection{Effect of the formulations on the extrusion processing parameters}

In the glassy carbohydrates, the low water content is needed to guarantee a $T_{\mathrm{g}}$ above $40^{\circ} \mathrm{C}$ at constant formulations while the extruder must work with high viscosity systems and provide considerable mixing. As given in Table 2, the torque percent of the premix materials ranged 13.82-15.09\%, which were found to be desirable for the extrusion of the formulations. Incorporation of trehalose to the maltodextrins could decrease the torque during extrusion, making extrusion more efficient. Die head pressures ranged from 10.56 to 13.19 bar, which is higher than that previously observed $(\sim 6.89$ bar) in the flavor encapsulation studies. In the current work, temperature of the hot molten material ranged $108.73^{\circ} \mathrm{C}$ to $111.92^{\circ} \mathrm{C}$ and residence time of material in the extruder was less than 3 minutes for all the samples (not shown in the Table).

Similar temperature conditions were recorded when sunflower oil-starch material was extruded (Yllmaz et al., 2001) in which the mix was treated at lower temperatures (less than $115^{\circ} \mathrm{C}$ ) compared to spray drying.

\subsection{Effect of the formulations on the physical characteristics of the extrudates}

AA content, moisture, AA yield, $T_{\mathrm{g}}$ and expansion ratio of the extrudates were recorded (Table 3 ).

As shown, AA yield of all samples was above $97 \%$, which indicated that this method can be employed to encapsulate AA with minimal losses as compared to other contemporary techniques (Desai \& Park, 2005; Pierucci et al., 2006). The Tg of glassy matrices determines its chemical stability, and physical stability, as well as viscoelastic properties (Hancock \& Zografi, 1994; Li et al., 2018).

It is believed that chemical stability of active materials is a direct function of the $T_{\mathrm{g}}$ of the dried product (Hatley \& Blair, 1999; Li et al., 2018). In our formulation, both water and AA are the potent plasticizers for extruded glassy products, which indicated that water content and AA loading percentage compromised the stability of extruded material. Maltodextrins based extrudate containing $15.59 \%(\mathrm{w} / \mathrm{w})$ of AA at $6.28 \%$ (w/w) water level showed $T_{\mathrm{o}}$ of $44.84{ }^{\circ} \mathrm{C}$. The incorporation of trehalose reduced the $T_{\mathrm{g}}$ while gum arabic had a slight effect on $T_{\mathrm{g}}$. All formulations had a low expansion ratio while the gum arabic-based extrudates offered reduced expansion ratio. Higher expansion ratio is undesirable as it is linked to the increased hygroscopicity of the extruded material.

Table 2. Pressure, torque, torque percent and material temperature in the extruder (TM1, TM2) during production of glassy extrudates using different formulations at the same processing conditions.

\begin{tabular}{cccccc}
\hline Series & Torque $(\mathrm{Nm})$ & Torque percent $(\%)$ & $\mathrm{TM}_{1}\left({ }^{\circ} \mathrm{C}\right)$ & $\mathrm{TM}_{2}\left({ }^{\circ} \mathrm{C}\right)$ & $111.92 \pm 0.38$ \\
\hline Formulation 1 & $25.04 \pm 1.30$ & $14.73 \pm 0.77$ & $109.39 \pm 0.21$ & $111.38 \pm 0.11$ & $10.56 \pm 2.92$ \\
Formulation 2 & $23.49 \pm 1.15$ & $13.82 \pm 0.68$ & $109.33 \pm 0.24$ & $111.52 \pm 0.07$ & $13.19 \pm 3.11$ \\
Formulation 3 & $25.65 \pm 1.44$ & $15.09 \pm 0.84$ & $108.73 \pm 0.22$ & (bar $)$ \\
\hline
\end{tabular}

Note: Results were means \pm SD of all the data recorded during extrusion; ${ }^{a}$ Die Head Pressure.

Table 3. AA content, moisture, AA yield, $T_{\mathrm{g}}$ and expansion ratio of the extrudates.

\begin{tabular}{|c|c|c|c|c|c|}
\hline${ }^{A}$ Series & $\begin{array}{c}\text { Water content of the } \\
\text { extrudate (\%) }\end{array}$ & $\begin{array}{c}\text { AA yield } \\
\text { (\%) }\end{array}$ & $\begin{array}{c}\text { AA content } \\
\text { (g/100g extrudate) }\end{array}$ & $\begin{array}{c}T_{g} \\
\left({ }^{\circ} \mathrm{C}\right)\end{array}$ & Expansion ratio \\
\hline 1 & 6.28 & 98.50 & 15.96 & 44.84 & 1.125 \\
\hline 2 & 6.57 & 98.36 & 15.89 & 40.89 & 1.127 \\
\hline 3 & 6.59 & 97.02 & 15.67 & 43.02 & 1.098 \\
\hline
\end{tabular}

${ }^{A} 1,2,3$ represents the formulation 1 , formulation 2 and formulation 3 , respectively. 


\section{3 $X$-ray diffraction analysis}

XRD studies helped to confirm whether the crystalline structure of the extruded AA was retained. The X-ray diffractograms of pure AA, premixed mixture of formulation 1 , extruded products of formulation 1, 2, 3 after extrusion, extruded products of formulation 1,2, 3 after 3 months storage at $40{ }^{\circ} \mathrm{C}$ are given in Figure 1. The characteristic crystalline peaks of AA were obtained at $2 \theta$ of $10.3,14.09,17.3,25.24,40.29,48.19$ and 54.3.

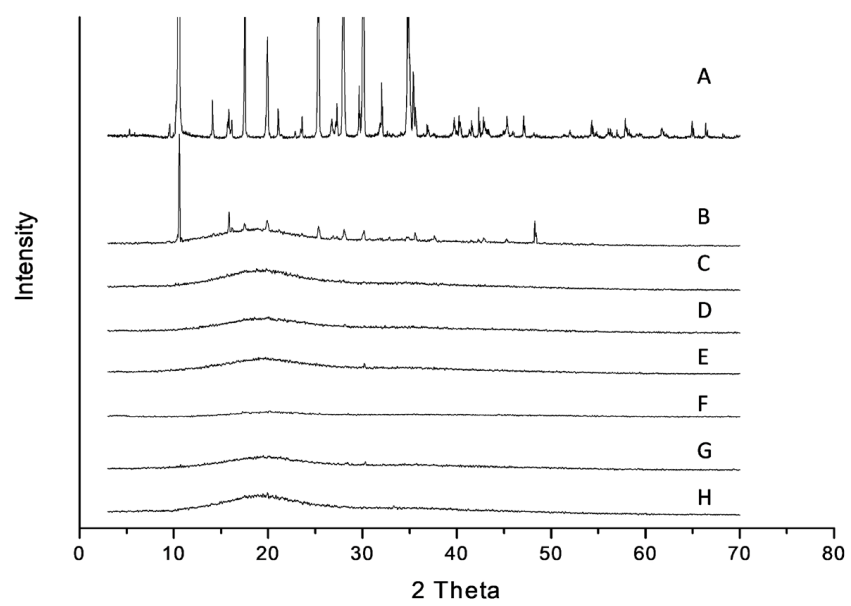

Figure 1. XRD spectra of (A) pure AA, (B) premix of formulation 1 (C) extruded product of formulation 1 (D) extruded product of formulation 2 (E) extruded product of formulation 3 (F) extruded product of formulation 1 after 3 months storage at $40^{\circ} \mathrm{C}(\mathrm{G})$ extruded product of formulation 2 after 3 months storage at $40^{\circ} \mathrm{C},(\mathrm{H})$ extruded product of formulation 3 after 3 months storage at $40^{\circ} \mathrm{C}$.
In addition, prepared premix of materials also exhibited the crystalline peaks (Figure 1B). While any characteristic crystalline peaks of AA were not observed in the extruded products, which indicated that AA was dispersed at the molecular level in the carbohydrate matrices. In a similar study, ketoconazole was dispersed in the extruded matrix (Dong et al., 2008). After storage at $40{ }^{\circ} \mathrm{C}$ for 3 months, no recrystallization could be detected in the milled extrudates, thus, indicating a good physical stability.

\subsection{FTIR analysis}

The FTIR spectrograms of pure AA, maltodextrin, premix of formulation 1, and extruded products of formulation 1, 2, 3 are shown in Figure 2. The characteristic peaks of pure AA were obtained at 1025, 1321, 1661, 1747, 3315, 3409 and $3525 \mathrm{~cm}-1$ (Figure 2A). The peaks at 3525, 3409, 3315, $3216 \mathrm{~cm}-1$ were assigned to the $\mathrm{O}-\mathrm{H}$ stretching vibration.

In the spectrum of the carbohydrates/AA extrudates, the peaks corresponding to $\mathrm{O}-\mathrm{H}$ stretching of AA become diffused and broadened (Figure 2D, 2E, 2F), which indicated that the formulation was in an amorphous form, and no significant chemical changes occurred. These findings were corresponding to that of extrudates containing celecoxib compound (Chawla et al., 2003; Sarode et al., 2013; Malaquias et al., 2018).

\subsection{Scanning electron microscopy}

The SEM images of the cross-section morphology of the extrudates are displayed in Figure 3. It was found that the pure AA existed as crystals with sharp edges (Figure 3A). The images

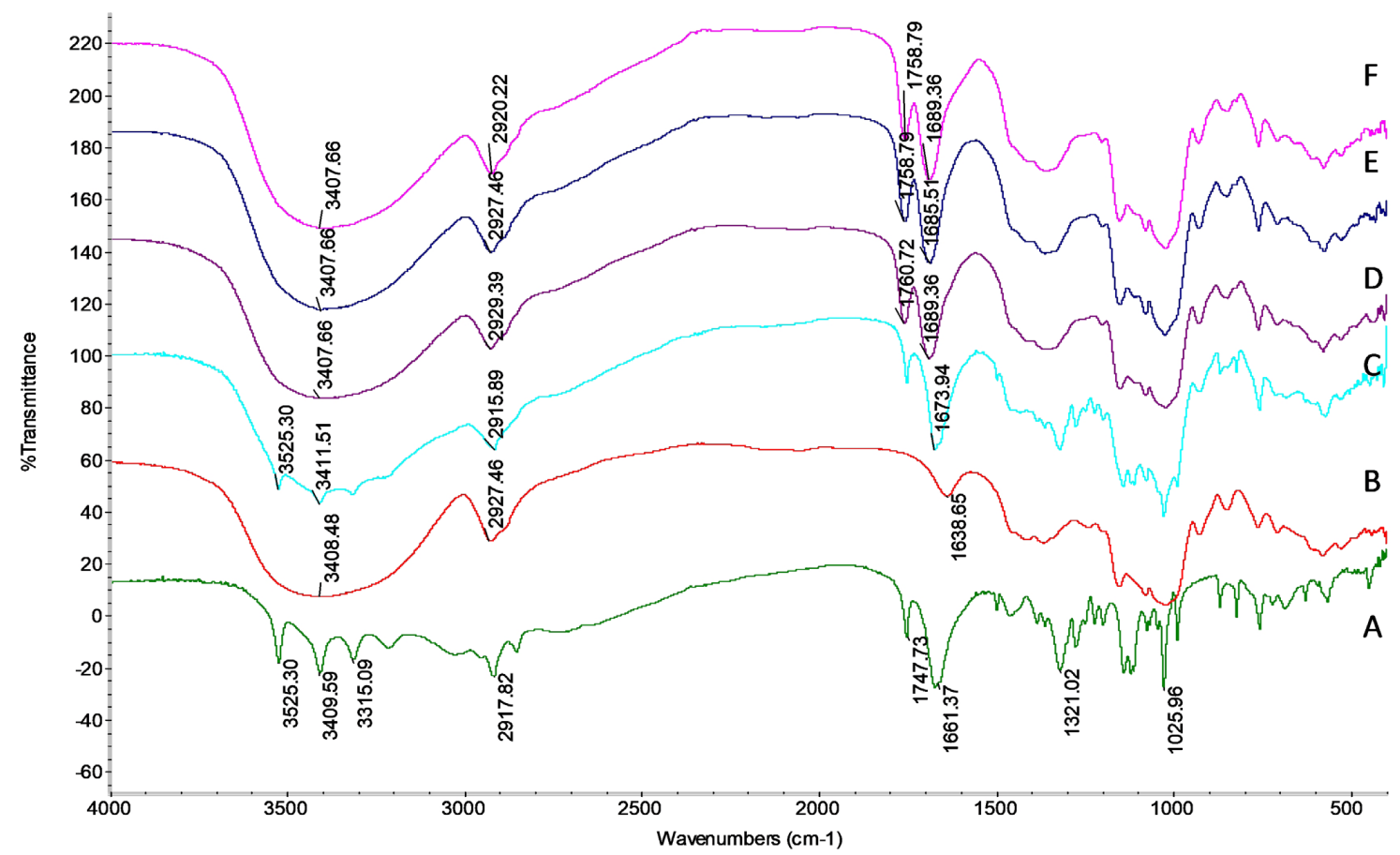

Figure 2. FTIR spectra of (A) pure AA (B) maltodextrin (C) premixed mixture of formulation 1 (D) extruded product of formulation 1 (E) extruded product of formulation 2 (F) extruded product of formulation 3. 


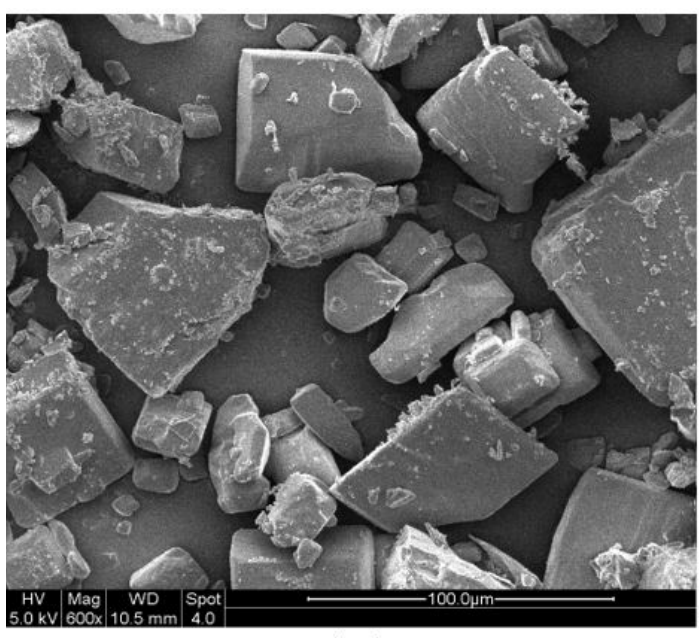

(A)

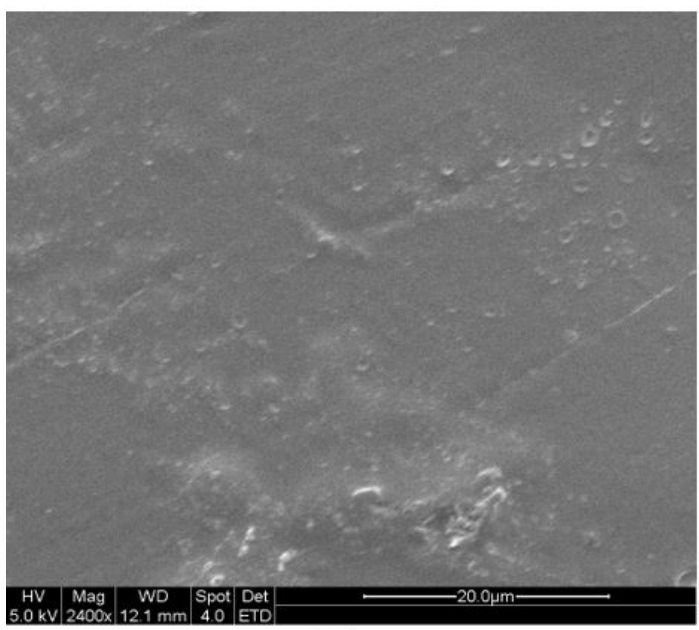

(C)

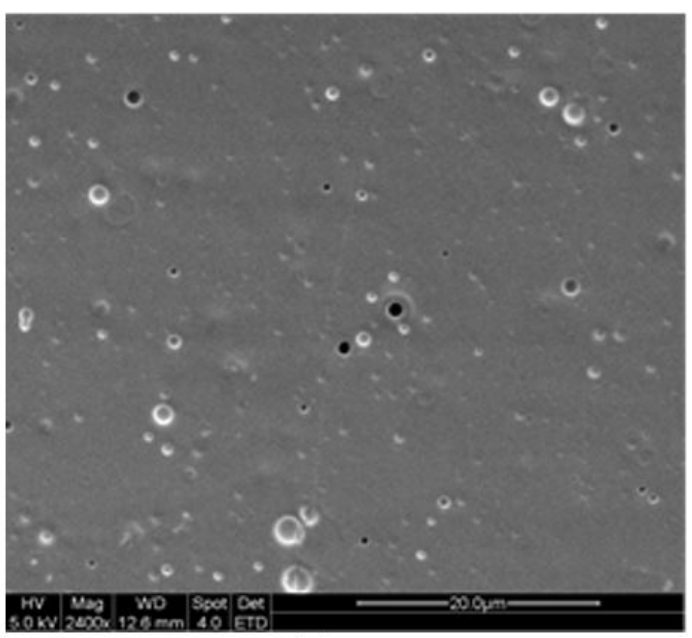

(B)

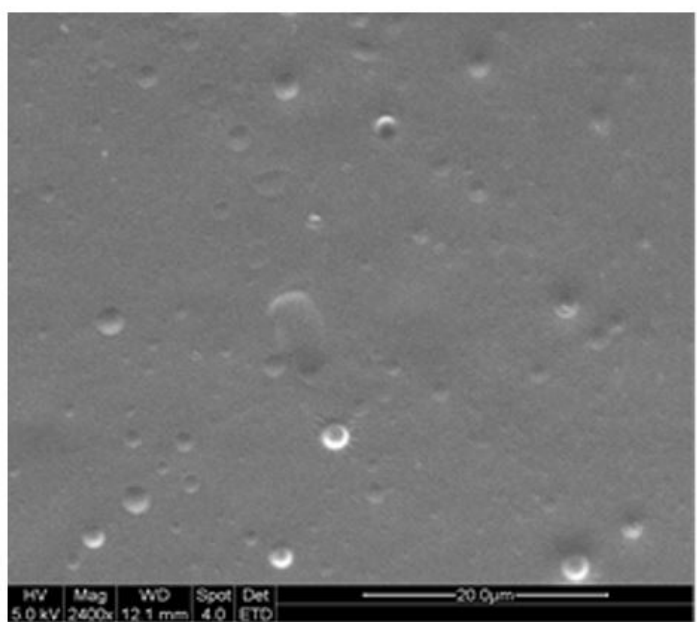

(D)

Figure 3. (A) SEM micrographs of the pure AA powder (B) Cross section morphology of the extrudates of formulation 1 (C) Cross section morphology of the extrudates of formulation 2 (D) Cross section morphology of the extrudates of formulation 3.

of all AA loaded extruded glassy products showed that there was no difference among them and did not reveal crystallization of AA (Figure 3B, 3C, 3D). It could be concluded that the AA was most likely molecularly dispersed within the carbohydrates suggesting AA/carbohydrates miscibility. This could be explained by the fact that if AA is in its crystalline form, the cross-section of the extruded glassy products would not have been smooth when viewed with SEM.

\subsection{Dissolution behavior of the extrudates}

The molecularly dispersed state of the AA might also attribute to the good content uniformity of the extruded glassy products. The SEM result was consistent with the results obtained from $\mathrm{XRD}$ and FTIR studies. These results agree with those reported previously in pharmaceutical formulation (Repka et al., 2003; Mididoddi \& Repka, 2007; Jaiswar et al., 2016). Dissolution profiles of three milled extrudates with particle size range of 20-40 mesh are shown in Figure 4.

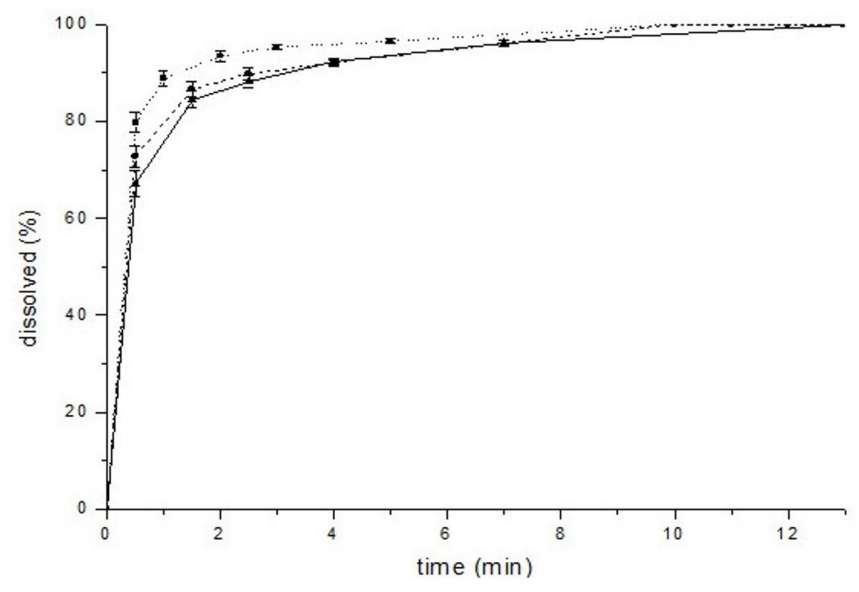

Figure 4. Dissolution profiles of milled extrudates which particle size in the range of 20-40 mesh. formulation 1 (dash line); formulation 2 (dot line) and formulation 3 (solid line). 
The pure AA was completely dissolved in less than 20 seconds (not shown). Results showed that three milled extrudates had a fast dissolution rate, and AA was completely dissolved within 10 min. Similarly, Cilurzo et al. (2008) reported that low DE maltodextrins formed fast dissolving films. However, there was difference in the initial release of AA for all three different formulations used. The higher the molecular weight material added to the maltodextrin, the lower dissolution rate of the initial release was. In polymer matrices, the release pattern depends mainly on the geometry of the system, the type of carrier material and the loading of the active agent (Pothakamury \& Barbosa-Cánovas, 1995). To describe the drug release mechanism from solid dispersions, two sets of observations were made in this work: carrier-controlled dissolution and drug-controlled dissolution. For the carrier-controlled dissolution, the rate of release was controlled by the carrier and was independent of the drug properties (Albers et al., 2009). In our research work, the dissolution mechanism of the milled extrudates could be explained based on the carrier-controlled dissolution phenomenon.

\section{Conclusion}

In this study, maltodextrin, maltodextrin-gum arabic and maltodextrins-trehalose microencapsulated AA powders were successfully prepared using the HME technique. Results explained the behavior of AA dispersed in the encapsulating matrix. The nature of the wall matrix affected the physical characteristics of extrudates. For instance, the incorporation of small molecular weight carbohydrate (trehalose) could decrease the $T_{\mathrm{g}}$, thus, making the extrusion processing more efficient. On the other hand, incorporation of high molecular weight carbohydrate (gum arabic) mainly reduced the expansion ratio. A significantly reduced dissolution rate of the maltodextrin-gum arabic and maltodextrins-trehalose microencapsulated powders compared to non-encapsulated AA suggests potentially good release profiles. FTIR, SEM and X-RD results proved that AA and carbohydrates were miscible, and they formed solid solution during the melt formation process. Overall, the extrusion technique employed in the study demonstrated that AA can be stabilized effectively in carbohydrate matrices. Results of this study also suggest that glassy matrices of maltodextrin-gum arabic obtained through HME can be extended to encapsulate other bioactives, including polyphenols.

\section{Acknowledgements}

Scientific Research Grant Foundation for doctors of Shaanxi University of Science and Technology (BJ11-13); Scientific Research Plan Projects of Education Department of Shaanxi Provincial Government (16JK1104) and Shaanxi Provincial Department of Science and Technology (2017NY-145) supported this work.

\section{References}

Abbas, S., Da Wei, C., Hayat, K., \& Xiaoming, Z. (2012). Ascorbic Acid: Microencapsulation techniques and trends - A review. Food Reviews International, 28(4), 343-374. http://dx.doi.org/10.1080/8 7559129.2011 .635390 .
Al-Kasmi, B., Alsirawan, M. H. D. B., Bashimam, M., \& El-Zein, H. (2017). Mechanical microencapsulation: the best technique in taste masking for the manufacturing scale - Effect of polymer encapsulation on drug targeting. Journal of Controlled Release, 260, 134-141. http:// dx.doi.org/10.1016/j.jconrel.2017.06.002. PMid:28603029.

Albers, J., Alles, R., Matthée, K., Knop, K., Nahrup, J. S., \& Kleinebudde, P. (2009). Mechanism of drug release from polymethacrylate-based extrudates and milled strands prepared by hot-melt extrusion. European Journal of Pharmaceutics and Biopharmaceutics, 71(2), 387394. http://dx.doi.org/10.1016/j.ejpb.2008.10.002. PMid:18951978.

Carr, A. C., \& Frei, B. (1999). Toward a new recommended dietary allowance for vitamin $\mathrm{C}$ based on antioxidant and health effects in humans. The American Journal of Clinical Nutrition, 69(6), 10861107. http://dx.doi.org/10.1093/ajcn/69.6.1086. PMid:10357726.

Chang, D., Abbas, S., Hayat, K., Xia, S., Zhang, X., Xie, M., \& Kim, J. M. (2010). Encapsulation of ascorbic acid in amorphous maltodextrin employing extrusion as affected by matrix/core ratio and water content. International Journal of Food Science \& Technology, 45(9), 1895-1901. http://dx.doi.org/10.1111/j.1365-2621.2010.02348.x.

Chawla, G., Gupta, P., Thilagavathi, R., Chakraborti, A. K., \& Bansal, A. K. (2003). Characterization of solid-state forms of celecoxib. European Journal of Pharmaceutical Sciences, 20(3), 305-317. http:// dx.doi.org/10.1016/S0928-0987(03)00201-X. PMid:14592696.

Chuah, A. M., Jacob, B., Jie, Z., Ramesh, S., Mandal, S., Puthan, J. K., Deshpande, P., Vaidyanathan, V. V., Gelling, R. W., Patel, G., Das, T., \& Shreeram, S. (2014). Enhanced bioavailability and bioefficacy of an amorphous solid dispersion of curcumin. Food Chemistry, 156, 227-233. http://dx.doi.org/10.1016/j.foodchem.2014.01.108. PMid:24629962.

Cilurzo, F., Cupone, I. E., Minghetti, P., Selmin, F., \& Montanari, L. (2008). Fast dissolving films made of maltodextrins. European Journal of Pharmaceutics and Biopharmaceutics, 70(3), 895-900. http://dx.doi. org/10.1016/j.ejpb.2008.06.032. PMid:18667164.

Desai, K. G. H., \& Park, H. J. (2005). Preparation of cross-linked chitosan microspheres by spray drying: Effect of cross-linking agent on the properties of spray dried microspheres. Journal of Microencapsulation, 22(4), 377-395. http://dx.doi.org/10.1080/02652040500100139. PMid:16214786.

DiNunzio, J., Forster, S., \& Brown, C. (2016) Melt extrusion: pharmaceutical applications. In M. Mishra (Ed.), Handbook of encapsulation and controlled release (Chap. 49, pp. 1127-1150). Boca Raton: CRC Press.

Dong, Z., Chatterji, A., Sandhu, H., Choi, D. S., Chokshi, H., \& Shah, N. (2008). Evaluation of solid state properties of solid dispersions prepared by hot-melt extrusion and solvent co-precipitation. International Journal of Pharmaceutics, 355(1), 141-149. http:// dx.doi.org/10.1016/j.ijpharm.2007.12.017. PMid:18243605.

Emin, M. A., Mayer-Miebach, E., \& Schuchmann, H. P. (2012). Retention of $\beta$-carotene as a model substance for lipophilic phytochemicals during extrusion cooking. Lebensmittel-Wissenschaft + Technologie, 48(2), 302-307. http://dx.doi.org/10.1016/j.lwt.2012.04.004.

Emin, M. A., \& Schuchmann, H. P. (2013). Analysis of the dispersive mixing efficiency in a twin-screw extrusion processing of starch based matrix. Journal of Food Engineering, 115(1), 132-143. http:// dx.doi.org/10.1016/j.jfoodeng.2012.10.008.

Gouin, S. (2004). Microencapsulation: industrial appraisal of existing technologies and trends. Trends in Food Science \& Technology, 15(7), 330-347. http://dx.doi.org/10.1016/j.tifs.2003.10.005.

Hancock, B. C., \& Zografi, G. (1994). The Relationship Between the Glass Transition Temperature and the Water Content of Amorphous Pharmaceutical Solids. Pharmaceutical Research, 11(4), 471-477. http://dx.doi.org/10.1023/A:1018941810744. PMid:8058600. 
Hatley, R. H. M., \& Blair, J. A. (1999). Stabilisation and delivery of labile materials by amorphous carbohydrates and their derivatives. Journal of Molecular Catalysis. B, Enzymatic, 7(1-4), 11-19. http:// dx.doi.org/10.1016/S1381-1177(99)00018-1.

Jaiswar, D. R., Jha, D., \& Amin, P. D. (2016). Preparation and characterizations of stable amorphous solid solution of azithromycin by hot melt extrusion. Journal of Pharmaceutical Investigation, 46(7), 655-668. http://dx.doi.org/10.1007/s40005-016-0248-x.

Li, R., Lin, D., Roos, Y. H., \& Miao, S. (2018). Glass transition, structural relaxation and stability of spray-dried amorphous food solids: A review. Drying Technology, 37(3), 1-14. http://dx.doi.org/10.1080 /07373937.2018.1454939.

Malaquias, L. F. B., Sá-Barreto, L. C. L., Freire, D. O., Silva, I. C. R., Karan, K., Durig, T., Lima, E. M., Marreto, R. N., Gelfuso, G. M., Gratieri, T., \& Cunha-Filho, M. (2018). Taste masking and rheology improvement of drug complexed with beta-cyclodextrin and hydroxypropyl- $\beta$-cyclodextrin by hot-melt extrusion. Carbohydrate Polymers, 185, 19-26. http://dx.doi.org/10.1016/j.carbpol.2018.01.011. PMid:29421056.

Massaux, C., Sindic, M., Lenartz, J., Sinnaeve, G., Bodson, B., Falisse, A., Dardenne, P., \& Deroanne, C. (2008). Variations in physicochemical and functional properties of starches extracted from European soft wheat (Triticum aestivum L.): The importance to preserve the varietal identity. Carbohydrate Polymers, 71(1), 32-41. http://dx.doi. org/10.1016/j.carbpol.2007.05.012.

Mididoddi, P. K., \& Repka, M. A. (2007). Characterization of hot-melt extruded drug delivery systems for onychomycosis. European Journal of Pharmaceutics and Biopharmaceutics, 66(1), 95-105. http://dx.doi. org/10.1016/j.ejpb.2006.08.013. PMid:17045468.

Milani, T. M. G., Menis, M. E. C., Jordano, A., Boscolo, M., \& ContiSilva, A. C. (2014). Pre-extrusion aromatization of a soy protein isolate using volatile compounds and flavor enhancers: Effects on physical characteristics, volatile retention and sensory characteristics of extrudates. Food Research International, 62, 375-381. http://dx.doi. org/10.1016/j.foodres.2014.03.018.
Pierucci, A. P. T. R., Andrade, L. R., Baptista, E. B., Volpato, N. M., \& Rocha-Leão, M. H. M. (2006). New microencapsulation system for ascorbic acid using pea protein concentrate as coat protector. Journal of Microencapsulation, 23(6), 654-662. http://dx.doi. org/10.1080/02652040600776523. PMid:17118881.

Pothakamury, U. R., \& Barbosa-Cánovas, G. V. (1995). Fundamental aspects of controlled release in foods. Trends in Food Science \& Technology, 6(12), 397-406. http://dx.doi.org/10.1016/S09242244(00)89218-3.

Repka, M. A., Prodduturi, S., \& Stodghill, S. P. (2003). Production and characterization of hot-melt extruded films containing clotrimazole. Drug Development and Industrial Pharmacy, 29(7), 757-765. http:// dx.doi.org/10.1081/DDC-120021775. PMid:12906333.

Sarode, A. L., Sandhu, H., Shah, N., Malick, W., \& Zia, H. (2013). Hot melt extrusion (HME) for amorphous solid dispersions: Predictive tools for processing and impact of drug-polymer interactions on supersaturation. European Journal of Pharmaceutical Sciences, 48(3), 371-384. http://dx.doi.org/10.1016/j.ejps.2012.12.012. PMid:23267847.

Silva, M. A., Albuquerque, T. G., Oliveira, M. B. P. P., \& Costa, H. S. (2018). Vitamin $\mathrm{C}$ evaluation in foods for infants and young children by a rapid and accurate analytical method. Food Chemistry, 267, 83-90. http://dx.doi.org/10.1016/j.foodchem.2017.11.046. PMid:29934193.

Tackenberg, M. W., Thommes, M., Schuchmann, H. P., \& Kleinebudde, P. (2014). Solid state of processed carbohydrate matrices from maltodextrin and sucrose. Journal of Food Engineering, 129, 30-37. http://dx.doi.org/10.1016/j.jfoodeng.2014.01.003.

Yılmaz, G., Jongboom, R. O. J., Feil, H., \& Hennink, W. E. (2001). Encapsulation of sunflower oil in starch matrices via extrusion: effect of the interfacial properties and processing conditions on the formation of dispersed phase morphologies. Carbohydrate Polymers, 45(4), 403-410. http://dx.doi.org/10.1016/S0144-8617(00)00264-2.

Yuliani, S., Torley, P. J., D’Arcy, B., Nicholson, T., \& Bhandari, B. (2006). Extrusion of mixtures of starch and d-limonene encapsulated with $\beta$-cyclodextrin: Flavour retention and physical properties. Food Research International, 39(3), 318-331. http://dx.doi.org/10.1016/j. foodres.2005.08.005. 